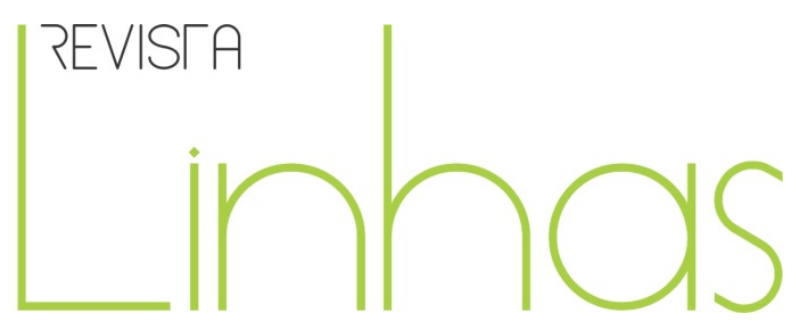

\title{
Em busca de respostas para as necessidades educacionais da sociedade atual. Uma perspectiva multidisciplinar da tecnologia ${ }^{1}$
}

\begin{abstract}
Resumo
Neste artigo, argumenta-se sobre a necessidade de integrar o conhecimento pedagógico disponível, evitando formas de visões reducionistas informadas pelo imperativo tecnológico e considerando ambientes de ensino e aprendizagem que tentam responder às necessidades educacionais da sociedade de hoje. Para isso, discute-se a importância de considerar novas maneiras de produzir 0 conhecimento; trata-se das implicações de uma linha de pensamento e ação baseada na primazia dos instrumentos e delibera-se sobre a dificuldade de separar o que está associado ao risco de converter os fenômenos que podemos estudar, ou contribuir para criar algo diferente do que eles são. $O$ artigo termina com a elaboração de uma proposta educativa, não somente baseada na utilização das novíssimas tecnologias da informação e da comunicação, como também na organização de um espaço físico e simbólico, em que cada aluno, ou aluna, possa encontrar um lugar para aprender.
\end{abstract}

Palavras-chave: Tecnologia. Transdisciplinariedade. Pesquisa em Educação.

\section{Para citar este artigo:}

SANCHO-GIL, Juana Maria. Em buscas de respostas para as necessidades educacionais da sociedade atual. Uma perspectiva multidisciplinar da tecnologia. Revista Linhas, Florianópolis, v. 14, n. 27, jul./dez. 2013. p. 09 -44 .

\section{DOI: $10.5965 / 1984723814272013009$}

http://dx.doi.org/10.5965/1984723814272013009

\footnotetext{
${ }^{1}$ Este artigo foi originalmente publicado na Revista Fuentes volumen 4, 2002 (I.S.S.N.: 1575-7072,) número dedicado ao "Tema monográfico: Las nuevas tecnologías em la Enseñanza". Este periódico é vinculado a Facultad de Ciencias de la Educación da Universidad de Sevilla. Tradução autorizada. Revisão da tradução Geovana Mendes Lunardi
} 


\title{
In search for answers to the educational needs of the contemporary society. A multidisciplinary perspective of technology
}

\begin{abstract}
Avoiding reductionist views informed by the technological imperative, when trying to implement learning environments to cope with the challenges and opportunities of now a days society. In order to achieve this aim, a set of issues has been considered. (a) The need of taking into account new approaches to knowledge production. (b) The consequences of a line of thought and action based on the supremacy of artefacts. (c) The risk This paper discusses the need of integrating available educational knowledge, of reducing complex phenomena converting them into something that does not fully represent them. The paper finishes delineating an educational proposal not only based on the use of the newest information and communication technologies, but on the arrangement of a physical and symbolic space in which each student can fine his or her place to learn.
\end{abstract}

Keywords: Transdiciplinary. Tecnnology anda perspective of technology. 


\begin{abstract}
"Atualmente, é impossível democratizar um conhecimento compartimentado e "transcendentalizado" por natureza. Mas, podemos considerar se não seria possível, mais à frente, pensar em uma reforma de pensamento que permitisse enfrentar o formidável desafio que nos traz o seguinte dilema: ou sofrer muito com o bombardeamento de inúmeras formações que nos chegam cotidianamente, através de jornais, rádio e televisão, ou então encomendarmos doutrinas que não retenham mais informações do que aquelas que as confirmam, ou são ininteligíveis, rejeitando, como erro ou ilusão, tudo o que as refuta ou lhes são incompreensíveis. O problema se coloca não somente para o conhecimento do mundo no diaa-dia, mas também para o conhecimento de todas as coisas humanas, bem como o conhecimento cientifico em si" - (Morin, 2000:22).
\end{abstract}

\title{
Introdução
}

Entendo o convite da Revista Fuentes como uma oportunidade para aprofundar e divulgar o trabalho de investigação e desenvolvimento que tenho realizado nos últimos anos (Sancho, 2002). Conforme refletido em minhas publicações, nos estudos levados a cabo, bem como na minha prática de docente, desde que comecei a trabalhar no âmbito da Tecnologia Educativa, no começo dos anos oitenta, tentei evitar visões reducionistas baseadas no "poder da ferramenta". Partindo do meu interesse e preocupação em encontrar as melhores propostas possíveis para fornecer uma resposta aos problemas da educação, defendi, promovi e desenvolvi campos multidisciplinares que mostram a complexidade das situações educativas. Parto da convicção de que a finalidade do conhecimento pedagógico, elaborado desde sempre pelas áreas das Ciências e da Educação, é a de favorecer a melhoria dos ambientes de ensino e aprendizagem e das práticas docentes. A partir dessa convicção, argumento a necessidade de se integrar o conhecimento pedagógico disponível, evitando visões reducionistas formadas pelo 
imperativo tecnológico, no momento de planejar ambientes educacionais que tentam dar uma resposta às necessidades dos indivíduos e da sociedade atual.

\section{Selecionar e articular o conhecimento para abordar os problemas}

Priorizar o interesse em problemas da Educação e não em problemas da Tecnologia Educacional, como o campo de estudo que complementa ou suplementa o da Didática, o currículo, ou a Organização Educacional, implica em não centrar-se somente em uma área de conhecimento, nem re-criar um metadiscurso disciplinar. Esta perspectiva exige um olhar interdisciplinar e integrador, no qual o próprio problema e sua representação assinalam o sentido das indagações e articulam as contribuições das disciplinas, ao mesmo tempo em que as nutre e enriquece.

Esta reflexão faz-se possível através da existência de modelos de produção de conhecimento, que afetam não somente o tipo de conhecimento que é produzido, mas também a forma como ele é criado, o contexto de produção no qual ele se realiza, o modo de organizá-lo, o sistema de recompensa que ele usa e os mecanismos que controlam a qualidade do que é produzido.

\section{Abordagem de novas formas de produção de conhecimento}

Atualmente, é possível vislumbrar dois modos de produção de conhecimento que tendem a dominar as representações atuais do conhecimento científico (Gibbons e outros. 1995). Estas duas formas de nos aproximarmos do conhecimento não são únicas, totais, nem exclusivas, nem devem ser consideradas uma divisão intransponível, mas sim, pontas extremas de algo contínuo. Recomenda-se não esquecer que as divisões que tratam de localizar campos de estudo têm, acima de tudo, a finalidade de organizar problemas, embora frequentemente induzam a um reducionismo que pode levar à confusão, ou ao dualismo maniqueísta, em vez de potencializar debates esclarecedores, que façam com que o próprio conhecimento avance. 
De acordo com Gibbons e outros (1995), a aproximação de como dois dos grandes quadros da produção do conhecimento científico se organizam na atualidade pode ser resumida como se segue.

\begin{tabular}{|l|l|}
\hline Modo 1 & Modo 2 \\
\hline
\end{tabular}

Tipo de conhecimento:

\begin{tabular}{|l|l|}
\hline Disciplinar. & . Multidisciplinar. \\
. Caracterizado pela homogeneidade. & . Caracterizado pela heterogeneidade. \\
$\begin{array}{l}\text {. Hierárquico e destinado a preservar a sua } \\
\text { forma. }\end{array}$ & $\begin{array}{l}\text {. Heterárquico e destinado a transcender a sua } \\
\text { forma. }\end{array}$ \\
\hline
\end{tabular}

Controle de qualidade:

\begin{tabular}{|l|l|}
\hline $\begin{array}{l}\text {. Qualidade: opinião dos colegas sobre as } \\
\text { contribuições dos indivíduos. }\end{array}$ & $\begin{array}{l}\text {. Qualidade: é determinada por um conjunto } \\
\text { de critérios mais amplos, que refletem a } \\
\text { composição variada do seu sistema de revisão. }\end{array}$ \\
$\begin{array}{l}\text {. Controle: Seleção minuciosa daqueles } \\
\text { considerados competentes para agir como } \\
\text { colegas. Tal seleção é determinada, em } \\
\text { parte, pelas contribuições prévias para a } \\
\text { disciplina. }\end{array}$ & $\begin{array}{l}\text { - Controle: Critérios complementares são } \\
\text { adicionados no contexto aplicativo, } \\
\text { incorporando uma gama diversificada de } \\
\text { interesses intelectuais, sociais, econômicos e } \\
\text { políticos. }\end{array}$ \\
\hline
\end{tabular}

Coerência:

\begin{tabular}{|l|l|}
\hline $\begin{array}{l}\text {. As normas sociais e cognitivas se adaptam } \\
\text { mutuamente e produzem conhecimento } \\
\text { disciplinar. }\end{array}$ & $\begin{array}{l}\text {.Emergem normas apropriadas para o } \\
\text { conhecimento multidisciplinar. }\end{array}$ \\
$\begin{array}{l}\text {. Coloca-se ênfase na criatividade individual } \\
\text { como a força motriz do desenvolvimento. }\end{array}$ & $\begin{array}{l}\text {.A criatividade se manifesta como um } \\
\text { fenômeno de grupo, no qual a contribuição } \\
\text { individual é parte do processo. }\end{array}$ \\
$\begin{array}{l}\text {. O conhecimento foi acumulado através da } \\
\text { profissionalização e da especialização } \\
\text { institucionalizada nas universidades. }\end{array}$ & $\begin{array}{l}\text {.O conhecimento foi acumulado através da } \\
\text { repetida configuração de recursos humanos, } \\
\text { em formas organizacionais temporárias e } \\
\text { flexíveis. }\end{array}$ \\
\hline
\end{tabular}


Estes autores conceituam o Modo 1 de produção do conhecimento como um conjunto de ideias, métodos, valores e normas, que foram desenvolvidos de acordo com o modelo Newtoniano de pesquisa empírica e de representação da realidade "objetiva”. Tal pesquisa e representação foram unidas por múltiplos campos de pesquisa de investigação, que fizeram com que sua prática fosse considerada como científica. Assim, esse Modo $^{2}$ resume um conjunto de regras sociais e cognitivas que deverão continuar auxiliando na produção, legitimação e difusão deste tipo de conhecimento, que se distingue pela sua união e por ter como alvo a própria comunidade científica ou, no aspecto tecnológico ou no "conhecimento aplicado", o mundo "interessado" da indústria. Por outro lado, o modo 2 reinterpreta esses padrões, com base no surgimento de novos problemas relacionados a situações reais, pressupondo uma colaboração entre a comunidade científica e os usuários, como um guia para a ação. Essa decisão afeta fundamentalmente os modos e o meios de se tornar público o processo e os resultados da pesquisa.

Esta divisão oferece uma polaridade inicial, tanto de ordem sociológica, como, acima de tudo, ontológica e epistemológica, que permite detectar duas perspectivas diferentes na representação do conhecimento e suas finalidades. O modo 1 é uma referência para a pesquisa em Ciências Naturais (especialmente em certos campos da Física, Química e certos campos da Biologia) e reflete-se também em outras disciplinas, como a Psicologia. Por outro lado, o Modo 2 representa alguns conhecimentos relacionados com os problemas "reais", que afetam de maneira direta os destinatários da investigação, o que os torna mais responsáveis socialmente e reflexivos sobre as consequências da própria investigação, que envolve um grupo diversificado de pesquisadores que colaboram em um problema definido em um contexto específico e localizado. As diferenças entre estes “dois modos” de conceber, organizar e divulgar o conhecimento pode ajudar a localizar algumas das minhas posições e expectativa

\footnotetext{
${ }^{2}$ Nota de revisão: a autora, ao colocar esta palavra em letra maiúscula, a destaca no sentido de modelo e vai referenciar os dois modelos com os quais vai trabalhar, utilizando-se para isso da nomenclatura Modo 1 e Modo 2.
} 
relacionadas com o desenvolvimento do presente trabalho, principalmente, pela natureza dinâmica, complexa e emergente de questões relacionadas com a educação.

Estas considerações refletem importantes mudanças nas concepções da pesquisa e conhecimento, no campo das ciências, reconhecidas como referência e guia para o que hoje é considerada uma investigação científica e técnica. O fato de não aparecer como núcleo para referências e modelos, bem como o fato de que a pluralidade seja a guia e que o vínculo com a realidade se separe dos purismos de estruturas metodológicas e de controles de qualidade, e que a interação de grupos, interesses e perspectivas disciplinares sejam uma constante, tudo servirá de pórtico para tornar explícita a perspectiva adotada neste trabalho.

\section{A necessidade de se articular visões integradas e complexas}

Um dos campos de estudo e de intervenção que precisa se situar mais no Modo 2 de produção do conhecimento é o da educação. Seria difícil de encontrar um campo mais multidisciplinar, mais caracterizado pela heterogeneidade e com mais necessidade de transcender a sua forma e encontrar a heterarquia. Parece impossível se pensar em uma área de estudo e aplicação que tenha tal necessidade de determinar a qualidade mediante critérios mais amplos, que refletem a vasta composição social de seu sistema de revisão, e ainda agregar, aos mecanismos de controle, critérios adicionais no contexto de aplicação, incorporando uma diversa gama de interesses intelectuais, sociais, econômicos e políticos. É improvável que encontremos outro contexto de estudo e intervenção mais carente e, ao mesmo tempo, adequado para buscar normas apropriadas para o conhecimento multidisciplinar, em que a criatividade se manifeste como um fenômeno de grupo, onde a contribuição individual é uma parte do processo e onde o conhecimento é acumulado através da repetida configuração de recursos humanos, em formas organizacionais temporárias e flexíveis.

Porque, de acordo com Morin (2000), há uma falta de adaptação cada vez maior, profunda e grave entre nossos conhecimentos discordantes, clivados, encaixotados em disciplinas e, por outro lado, temos ainda algumas realidades e problemas, cada vez mais 
multidisciplinares, transversais, multidimensionais, transnacionais, globais e planetários. Porque cada vez mais se tornam visíveis os conjuntos complexos, as interações e realimentações entre as partes e o todo, as entidades multidimensionais e os problemas essenciais. Pois, como argumentam Aurelio Pecci e Daisaku Ikeda:

"A abordagem reducionista refere-se somente a uma série de fatores para organizar a totalidade dos problemas colocados pela crise multiforme que atravessamos atualmente. Há menos solução do que problema, em si”. (em Morin, 2000:15)

Desta maneira,

\begin{abstract}
"Quanto mais multidimensionais se tornam os problemas, maior é a incapacidade de se considerar a sua multidimensionalidade; quanto mais avança a crise, mais avança a incapacidade de se pensar na crise; quanto mais universais se tornam os problemas, menos refletidos estes serão. Uma inteligência incapaz de considerar o contexto e o complexo universal nos torna cegos, inconscientes e irresponsáveis" (Morin, 2000:15).
\end{abstract}

Para este autor, os desenvolvimentos disciplinares das ciências têm contribuído não somente com as vantagens da divisão de trabalho, mas também com os inconvenientes da superespecialização, a limitação e a fragmentação do conhecimento. Não somente produziram o conhecimento e o saber, como também a ignorância e a cegueira. Se for este o caso da maior parte das áreas de estudo e aplicação, no que diz respeito à educação, o problema parece ser ainda mais agudo, pois os próprios sistemas de ensino e as super-estruturas burocráticas que os controlam, em vez de corrigirem tais desenvolvimentos, só aumentam os mesmos.

Somos ensinados, desde a escola infantil, a isolar os objetos (do ambiente), a separar as disciplinas (em vez de reconhecer sua solidariedade), a fragmentar os problemas, em vez de unir e integrar. Devemos reduzir o complexo ao simples, ou seja, separar o que está unido, quebrar, em vez de reconstruir, eliminar tudo que nos traz transtorno ou contradições à nossa compreensão. 
No entanto,

\begin{abstract}
"Dado que todas as coisas são causadas e causam, ajudadas e ajudantes, mediatas e imediatas, e todas elas estão interligadas por um laço natural e insensível, que une os mais distantes e mais diferentes, considero impossível conhecer as partes sem conhecer o todo. É o mesmo que conhecer o todo sem conhecer particularmente as partes" (Pensées, Ed. Brunschvig, II, 72). (Em Morin, 2000:31).
\end{abstract}

\title{
Mas devemos também levar em consideração que
}

"Para pensar globalmente, temos que saber pensar localmente (Morin, 2000:31)".

Talvez por isso, e de forma paradoxal, atualmente, são as ciências humanas, incluindo as da educação, as que contribuem de forma mais fraca para o estudo da condição humana, precisamente porque elas são separadas e compartimentadas. No campo específico da educação, como argumentei em um trabalho anterior (Sancho, 1998), esta dificuldade poderia encontrar-se na constatação de que as novas visões da ciência (o paradigma do pós-modernismo, da complexidade, teoria do caos, etc.) não conseguiram transferir o imaginário educacional, nem mesmo no nível da investigação e dos estudos teóricos.

Do acima mencionado, deriva a minha proposta de tentar integrar o conhecimento sobre a educação até onde nos seja possível e razoável, e que tal seja feito desde a Tecnologia Educacional. Por este motivo, considero um tema fundamental do presente artigo focar os maiores problemas da educação na sociedade de hoje. Esta abordagem me permite construir pontes entre as diferentes perspectivas sobre educação, convertidas em campos disciplinares. Por isso, apoio-me no conhecimento educacional acumulado, com o objetivo de demonstrar a dificuldade em estabelecer distinções disciplinares, quando tratamos de propostas educacionais colocadas em prática.

Uma aproximação aos conhecimentos educacionais disponíveis mostra como os autores e as autoras que programaram suas ideias sobre a educação, os movimentos pedagógicos e os docentes reflexivos, não conseguem elucidar se as decisões tomadas e os conhecimentos de que precisam são uma herança da Didática, da Organização Educacional, do Currículo, da Tecnologia Educacional, da Arquitetura, ou da Cultura 
Visual. Neste sentido, a prática educativa fundamentada em um planejamento rigoroso, e baseada no conhecimento disponível, constitui, por natureza, um âmbito de conhecimento representativo do Modo 2, no qual o conhecimento é o resultado de uma série de considerações situadas fora do âmbito das disciplinas. É profundamente multidisciplinar, possuindo, portanto, o quadro global de trabalho que orienta os esforços na solução de problemas. Um quadro que se gera e se sustenta no contexto da prática, no qual se produz uma separação entre o desenvolvimento e sua aplicação, para que a solução não surja de maneira isolada na utilização de conhecimentos que já existem.

A desintegração e a fragmentação deste conjunto de conhecimentos parecem ocorrer posteriormente e no âmbito acadêmico. Trata-se de um lugar distante das problemáticas reais, e onde os mecanismos de poder e controle de parcelas do conhecimento parecem nos preocupar mais do que a nossa incidência sobre os verdadeiros problemas da educação. Considera-se que este processo de compartimentação e hierarquia de conhecimento, em que aqueles que têm o controle das instituições determinam a legitimidade das propostas, chegando-se até mesmo a se argumentar sobre a idoneidade das pessoas para abordar problemas específicos de estudo, pertence à outra área do conhecimento, como afirma Morin (2000:15). Quem sabe, seja isso que dificulte a abordagem dos problemas cada vez mais multidimensionais, o que nos torna cada vez mais “cegos, inconscientes e irresponsáveis".

Nesta perspectiva, tanto a reconstrução dos conhecimentos, habilidades e técnicas utilizadas e produzidas na prática educativa, como a implementação de propostas teóricas, a partir do campo das Ciências da Educação, podem ser levadas a cabo, sem detrimento das disciplinas de referência e de sua posição nas áreas de conhecimento reconhecidas nas distintas universidades, a partir de qualquer perspectiva ou ponto de partida. Neste caso, tal reconstrução e implementação são levadas a cabo a partir da Tecnologia Educacional. 


\section{A primazia dos instrumentos}

Geralmente, é atribuída a Herbert A. Simon, um dos mais proeminentes estudiosos e promotores das "ciências do artificial”, a frase "é mais fácil se espalhar os instrumentos do que as ideias". Esta noção emerge claramente no estudo de propostas de aprimoramento educacional em toda a história e na atualidade. Não é difícil de encontrar nas práticas de ensino de qualquer ciclo de aprendizagem de técnicas, recursos, materiais e equipamentos que são utilizados de forma descontextualizada, em muitas ocasiões, longe da filosofia e da perspectiva educativa, a partir da qual foram desenvolvidos ou se originaram. A organização dos alunos em grupos, quando na realidade não trabalham em equipe, nem realizam tarefas colaborativas, o uso de "técnicas" e recursos freinetianos, que assinalam noções de educação popular e democrática do seu autor, ou a distribuição das classes em forma de "U”, mesmo que a prática de aprendizagem não seja entendida como uma conversação contínua, em que todo o saber é objeto de debate e interpretação, são alguns dos muitos exemplos do conceito que tentamos ilustrar.

Esta constatação nos permite realizar uma série de considerações que delineiam a perspectiva abordada por este artigo. A primeira se refere ao fato de que, na história da Educação, o desenvolvimento, a apropriação, ou a adaptação de recursos e instrumentos para o ensino, foram levados a cabo, em geral, a partir do desejo ou da necessidade dos distintos autores e autoras de colocar em prática as suas ideias pedagógicas. A característica comum daqueles que são considerados grandes pedagogos e pedagogas, desde Amos Comenio a Paulo Freire, assim como de milhares de docentes inovadores, foi, e é, a de encontrar a melhor forma, os melhores métodos e os recursos materiais para dar respostas aos problemas da educação.

A segunda consideração tem a ver com a ruptura entre a linha de integração de ideias e os recursos pedagógicos que se vislumbravam, nos anos sessenta, nas propostas de melhoria de ensino nos Estados Unidos, um país que deposita grande confiança nos instrumentos produzidos. O principal representante dessa tendência é o psicólogo comportamental B.Frederick Skinner. Sua resposta aos problemas do ensino seria uma máquina de ensino. A influência da Psicologia, ou os conceitos sobre a natureza da 
infância e sobre os meios de aprender, vinham sendo, desde o século XVII, um pano de fundo para a educação. O surgimento da denominada Pedagogia Científica, que tentava derivar a prática docente de várias teorias científicas, especialmente as da psicologia, mas também das teorias da comunicação, gestão, etc., representa um marco nesta perspectiva. Neste contexto, no início dos anos sessenta, do século XX, no contexto da guerra fria e em clima de total confiança na ciência e na tecnologia, que era entendida como a possibilidade de se resolver qualquer problema humano com técnicas e máquinas derivadas das descobertas científicas, não é de se estranhar o aparecimento de uma “máquina de ensino", separada de uma filosofia de educação e de alguns fins educacionais.

O que é relevante neste aspecto, e para a perspectiva deste estudo, é que, apesar do fracasso da proposta de Skinner e os resultados de centenas de estudos, mostrando que o uso destas máquinas não significaria uma melhoria no desempenho dos alunos e, muito menos, na aprendizagem em longo prazo, as ideias de Skinner continuam a emergir como um pilar fundamental de algumas visões de Tecnologia Educacional e Didática. Além disso, a crença de que uma máquina, agora digital e com desempenho extraordinário para tratar a informação, pode melhorar e se tornar uma resposta para os problemas da educação continua vigente. Neste aspecto, têm contribuído significativamente, por um lado, a extensão e o reforço de comportamentos e mentalidades governadas por um imperativo tecnológico e, por outro lado, o impacto social, político e cultural formidável, produzido pelas tecnologias da informação e comunicação, desenvolvidas durante o século XX: desde o telefone até a televisão e o vídeo, mas, acima de tudo, o computador e todos os seus derivados. A evolução do computador e o desenvolvimento da perspectiva de estudo, como da inteligência artificial, contribuíram para acrescentar a configuração desta ferramenta como um recurso cognitivo privilegiado, além da crença de que a sua utilização representa, por si só, uma inovação em qualquer campo (Noble, 1991).

Esta situação permitiu a muitos teóricos e práticos da educação pensar em “soluções tecnológicas”, com base na utilização de máquinas e aparelhos, social, política 
e educacionalmente fora do contexto, promovendo a existência de propostas para o uso dos mais modernos dispositivos, sem dimensão organizacional, curricular, didática. Nesta perspectiva, cada novo desenvolvimento no domínio das tecnologias da informação e comunicação é apresentado como "a resposta aos problemas do ensino". No entanto, uma elevada porcentagem de aplicativos educacionais baseados em sistemas informáticos continua utilizando princípios de representação do conhecimento de ordem fatual e conceitual e, portanto, desordenados na parte autônoma, para a qual se podem estabelecer claramente requisitos e objetivos. Neste contexto, especialmente na escola primária e secundária, os programas mais difundidos são os de “prática e exercícios".

Por outro lado, o aumento da complexidade das aplicações derivadas das tecnologias contemporâneas da informação e comunicação requer o domínio de linguagens e técnicas específicas, e levam à necessidade de estabelecer uma colaboração com diferentes profissionais. Se não for assim, pode acontecer, como está acontecendo com as reformas educativas sendo implementadas, uma tentativa de se desafiar sistemas de ensino, para tentar melhorar os existentes, e não se leve em consideração os recursos disponíveis na sociedade, não somente do ponto de vista de sua possível utilização nos processos de ensino e aprendizagem, mas também por seu impacto em todos os âmbitos da sociedade, incluindo as necessidades educativas e de formação da população.

Os acontecimentos se traduzem em uma particular importância, em um momento em que a tendência do desenvolvimento da sociedade atual tem levado a uma caracterização da mesma, como Sociedade da Informação (Castells, 1998), o que deixa à educação uma série de desafios difíceis de abordar, desde as disciplinas pedagógicas. Neste momento, está em questão a própria metáfora organizacional da escola, tal como nós a conhecemos, nos últimos duzentos anos. Hoje, os desafios dos sistemas educativos passam pela necessidade de articular ambientes de aprendizagem diversificados, que percebam as transformações experimentadas na forma de elaborar e acessar o conhecimento, propiciadas pela proliferação e extensão das tecnologias da informação e da comunicação. 


\section{A dificuldade de separar o que está unido}

Em um trabalho anterior (Sancho, 2002), continuei a fornecer elementos que fundamentam a necessidade de se integrar o conhecimento para responder às necessidades e desafios da educação. Na verdade, quando isso não acontece, a proposta educacional fica consideravelmente diminuída. Este é um dos problemas enfrentados pela visão de Tecnologia Educacional de corte de instrumento, que não considera a especificidade dos objetivos de aprendizagem, nem a seleção, coordenação e representação do conhecimento e a maneira de organizar a interação didática. Para muitos autores, especialmente os europeus, isto significaria uma dependência disciplinar da Tecnologia Educativa, no que diz respeito à Didática. Contudo, nos últimos vinte anos, o estudo sobre as problemáticas do ensino, do ponto de vista do campo de estudo do “Curriculum”, estabeleceu as possíveis relações de dependência, interdependência, complementaridade e poder de suplementação entre a Didática e o Curriculum. Por motivos de tempo e coerência com o objetivo deste artigo, não entrarei neste debate. Deste modo, partindo da perspectiva adotada para caracterizar os problemas da educação, o que argumento é a necessidade de se encontrar sinergias, complementos e inter-relações entre os mais diferentes conhecimentos disponíveis, para solucionar, da melhor maneira possível, os problemas da educação.

Desde o século $X X$, o âmbito da educação tem sido testemunha de um duplo fenômeno. De um lado, o processo impagável da globalização trouxe uma maior circulação de ideias e perspectivas, resultante da investigação e das propostas educativas, embora o fluxo desse intercâmbio tenha sido mais unidirecional do que multidirecional. Ou seja, dos países de língua inglesa para o resto do mundo. Por outro lado, as diferentes perspectivas sobre a melhor forma de planificar, implementar e avaliar propostas educacionais, a fim de fornecer respostas às exigências sociais e necessidades de formação dos indivíduos, têm se consolidado como áreas disciplinares ou campos de estudo. Uma consolidação que, como explicam autores, como Foucalt (1991, 1992) e Goodson (2000), implica na criação de parcelas de poder, princípios de regulamentos e 
um desejo de enfatizar mais o que se separa, pois nisso se baseia o status quo, mais do que aquilo que une ou complementa.

Nos últimos anos, em nosso contexto, produziu-se um aumento considerável da influência do pensamento anglo em relação aos temas da educação. Desde a década de oitenta, começou-se a traduzir as fecundas contribuições no campo de estudo do Curriculum, realizado nos anos sessenta, mas especialmente na década de setenta. 0 currículo não é concebido como um plano ou programa de estudo, mas como o campo de debate sobre o significado e as consequências da educação, a possibilidade de transformá-la, a necessidade de se abordar a fenda crescente entre o conhecimento disciplinar e o conhecimento popular e, acima de tudo, a possibilidade de solucionar o crescente problema de alfabetizar toda a população em escolas integradas. Ou seja, não fazer distinção de alunos, devido à classe social ou capacidade intelectual.

Esta onda de influência foi encontrada na Espanha, por meio de uma proposta de uma reforma da educação, onde o curriculum voltaria a ser um programa de estudo e não um “campo de debate”. Assim, as alegadas contribuições desta linha de pensamento foram minimizadas pela discussão, a rejeição ou a aceitação crítica de "uma" proposta que representava "uma" forma de compreender o planejamento do ensino. Neste processo, encontra-se um paralelismo relativo com o que aconteceu nos finais da década de sessenta, com a "Tecnologia Educacional", momento em que a "Lei Geral da Educação" assumiu uma forma de porta de entrada para as propostas de racionalidade e eficácia no planejamento da aprendizagem, provenientes dos Estados Unidos, assim como o uso dos meios da revolução da informação.

Estas situações levaram a diferentes autores no âmbito da Didática a estabelecerem o sentido das relações com as novas concepções sobre a educação e toda a sua contribuiçãao que, em outros países, encontram-se mais definidas como campos de estudo do que como disciplinas.

No entanto, na prática, existe uma grande dificuldade para estabelecer diferenças claras entre as três principais áreas de estudo, denominadas Didática, Curriculum e Tecnologia Educacional. Isto não significa que devemos desconsiderar as tradições de 
diferentes países e áreas geográficas, ou as tendências e perspectivas sobre a teoria e prática da Cultura da Universidade. Mais do que tudo, o reconhecimento de complementaridades e sobreposições entre essas áreas de estudo e prática pode significar o surgimento e crescimento de visões mais abrangentes e complexas, quando se trata de lidar com os problemas da educação na sociedade de hoje. Isto porque a multiplicidade de problemáticas que a educação tem que atender hoje não nos permite desconsiderar o conhecimento acumulado.

No que se refere à Tecnologia Educacional, para Davis (1996), a tecnologia, ao contrário da crença popular, não está necessariamente confinada a ser o meio pelo qual os educadores alcançam os fins. A tecnologia também levanta questões sobre a natureza dos próprios fins. Isto nos faz refletir sobre a moralidade das nossas ações, por sua própria insistência na escolha defensável de opções distintas. Pelo fato de se alargar o leque de possibilidades, a tecnologia e a educação nos tem levado a refletir e, por vezes, a reconsiderar a maneira em que tal seleção é feita, como também o propósito para o qual ela é feita.

Este autor identifica três abordagens para a Tecnologia Educacional. A TE um é essencialmente uma aproximação «de suporte físico», que coloca ênfase na importância das ajudas (meios) de ensino. Suas origens se encontram na aplicação das ciências físicas e da engenharia nos problemas de educação. Este conceito tende a dominar a maioria da literatura clássica da TE. Assume-se que uma tecnologia de máquinas está em íntima relação com a tecnologia educacional, e que progressivas visões de ensino estão, portanto, muito relacionadas com o último projetor, laboratório de idiomas e computador. A partir desta visão, a tecnologia é um meio de mecanizar ou automatizar o processo de ensino, com instrumentos que transmitem, expandem, distribuem, gravam e reproduzem estímulos materiais e, assim, aumentam o impacto do professor, assim como o público em potencial.

A TE dois é essencialmente uma aproximação de "suporte lógico", que dá ênfase à importância da ajuda à aprendizagem. Suas origens estão na aplicação das ciências do comportamento para os problemas da educação. Este conceito também parece dominar 
a maioria dos trabalhos escritos atuais sobre a TE, em particular, nas áreas de curriculum, desenvolvimento de cursos e planificação do ensino. Pressupõe-se que uma tecnologia de design de mensagem (baseada firmemente na definição de metas, análise de tarefas, princípios de motivação e avaliação) está no cerne da aprendizagem eficaz. A tecnologia é vista como um meio de se fornecer o necessário 'saber como' para o novo projeto, ou uma renovação que forneça experiências valiosas de ensino. As máquinas e mecanismos são vistos como meros instrumentos de apresentação ou transmissão.

A TE três combina as duas aproximações anteriores. Ela rejeita o desenvolvimento sistemático (por exemplo, o passo a passo e procedimentos rigidamente mecânicos) como a única forma de se proceder, a favor de um conjunto sistêmico de procedimentos (por exemplo, orgânicos mais que mecânicos), que foca mais nos processos do que nos resultados da aprendizagem. Ela aplica os conceitos de análise de sistemas no domínio da educação, ao mesmo tempo em que tende a se concentrar mais no indivíduo em si, no grupo ou equipe em que este representa um papel. A qualidade e a relevância da experiência global é uma das principais preocupações desta TE, assumindo que o ambiente em que o ensino e a aprendizagem se encontram é tão importante quanto os próprios processos. Nas instituições de ensino, a autoridade e a organização, na medida em que elas estão relacionadas aos aspectos curriculares e orientação e afetam os indivíduos, os grupos e a comunidade são também áreas de interesse. Tudo isso faz parte de um todo, ou de um sistema vivo, e a "saúde" do sistema é um tópico de grande interesse, não somente para seu bem-estar, mas também para a sua sobrevivência.

Esta última perspectiva é configurada como uma abordagem multidisciplinar e claramente localizada no modo 2 de produção de conhecimento, que não pode ser implementado sem o conhecimento desenvolvido a partir do campo da Didática, do Curriculum, da Organização Educacional e de outras Ciências da Educação.

De fato, se uma das funções da Didática consiste em explicar e compreender para propor (Contreras, 1990), a explicação e compreensão ficarão incompletas se não se levarem em conta a sociedade em que vivemos. A "proposição" envolve sempre um "modo de fazer" e a utilização de alguns meios. Desta forma, desde uma dimensão não reducionista, qualquer projeto educacional necessita, no mínimo: 
- Conhecer os prós, contras e os paradoxos que movem a sociedade atual, localizar os focos de poder e analisar o significado das ações que contribuem para transformar o mundo.

- Compreender como o mundo em que vivemos modela a cognição, o desenvolvimento, a afetividade e a compreensão dos indivíduos. Não apenas daqueles que estão começando o processo de socialização e educação, mas também todos aqueles que têm de lidar com novas situações. Ou seja, quase todos eles.

- Analisar o efeito transformador dos novos suportes de informação, nas formas de desenvolver, representar, armazenar, transmitir e obter conhecimento.

- Perguntar se as dimensões organizacionais, simbólicas e instrumentais que configuram a escola atual são "a tecnologia mais adequada" para se promover o tipo de educação que a sociedade, com maior ou menor grau de democracia, representação e participação, deseja garantir aos cidadãos.

Isso não significa ter que terminar por decreto e bruscamente com as divisões, as construções, as especializações e áreas do conhecimento acadêmico desenvolvido durante anos. Mas é um convite para se superar os limites inerentes a disciplinas, assinaturas, especialidades e áreas de estudo, tentando se passar para o Modo 2 de produção de conhecimento. É uma sugestão que enriquece os campos de investigação e de intervenção da complementaridade e o estabelecimento de relações com outras perspectivas. Esta visão nos permite abordar as conexões, relacionamentos, sobreposições e as diferenças entre a Didática, a Tecnologia Educacional e o campo de estudos do currículo.

Esta é a maneira de se tentar superar as tensões no assunto de Tecnologia Educacional, que divido com os alunos de Pedagogia. Seguindo a tradição acadêmica do nosso contexto, abordo a TE desde a sua vertente de instrumento, sobretudo, desde as tecnologias da informação e da comunicação. Porém, o olhar, o sentido da reflexão e o conteúdo das atividades de aprendizagem tentam promover nos alunos a capacidade de estabelecer relações, de compreender o processo de ensino e aprendizagem como um 
problema complexo e global, cuja abordagem precisa de todos os conhecimentos pedagógicos disponíveis que, em parte, estudam o conjunto de disciplinas que compõem o plano de estudos, sobretudo, na área da Didática e da Organização Educativa. Em suma, deixo-os descobrir e praticar a visão do conhecimento como multiplicação e não como divisão. Uma linha de pensamento que se concretiza na proposta para a criação de ambientes de aprendizagem diversificados, que levem em conta, além do conhecimento e dos recursos disponíveis, os problemas da sociedade contemporânea.

\section{Em busca de respostas para as necessidades e desafios educacionais da sociedade de hoje}

Cada momento histórico teve que considerar e responder a uma série de questões e desafios em relação à educação. O século XX pode ser caracterizado como o da consolidação dos sistemas escolares estatais. Desde a segunda guerra mundial, o processo de regulamentação, a legislação e a burocratização dos sistemas de ensino seguiram um curso definitivo e ascendente. Esta situação tem levado a um número infindável de melhorias no acesso à educação básica ou obrigatória por todos os grupos sociais, incluindo até mesmo os grupos tradicionalmente menos considerados, como os das pessoas com necessidades educacionais especiais, os imigrantes, ou os grupos marginais. Mas, neste processo de melhoria, ainda há questões em aberto que impedem a evolução da escola no ritmo exigido pelo progresso da sociedade.

A primeira questão diz respeito à falta de autonomia dos centros para desenvolver e implementar o seu próprio projeto educativo, em função das necessidades dos alunos. A segunda tem a ver com o pouco espaço de manobra para que os professores introduzam mudanças ou inovações substanciais em seus sistemas de ensino.

Esta situação explica a dificuldade de desenvolver e implementar propostas globais, que integram alguns fins educacionais amplamente compartilhados, além de alguns princípios de ação para implementá-las na prática, que consideram as dimensões organizacionais, simbólicas e de instrumento de ambientes de ensino, que podem responder às necessidades educacionais da sociedade de hoje. Parte-se da ideia 
questionável de que a única eventual organização de ensino é a que temos praticado nos últimos cento e cinquenta anos: um edifício dividido em turmas fechadas, em que grupos de crianças e jovens da mesma idade aprendem uma fração de um conjunto de matérias, alguns dias por semana, em sessões de cinquenta minutos. Qualquer inovação nesta estrutura poderosa é, no melhor dos casos, uma ação de maquiagem.

\section{Uma demanda crescente}

A situação anterior contrasta com a tendência de crescimento dos últimos anos, que defende a necessidade de mudanças profundas na escola atual (Sancho, 2000). Todos os setores, sobretudo, o empresarial e o das organizações supranacionais , que são aqueles que têm mais poder para ouvir a sua voz, têm publicado estudos, relatórios e propostas para mostrar evidências desta necessidade de mudança e para sugerir um caminho para tal mudança. Não faltam vozes de intelectuais e acadêmicos. E, embora suas ideias não incluam, com exceções, a publicação de livros, muitos docentes, especialmente no nível secundário, também estão convencidos de que as coisas têm de mudar.

Os fatores que converteram a escola atual em um lugar onde se é difícil responder às necessidades e demandas educacionais dos indivíduos e da sociedade atual são múltiplos e os resumiremos como segue.

- A diversidade da população que tem que frequentar a escola.

- O aumento exponencial da informação e do conhecimento disponível.

- A proliferação e a disseminação das tecnologias da informação que vieram a aumentar o universo de socialização dos alunos.

- A mudança no tipo de conhecimento e nas habilidades necessárias para nos incorporarmos à sociedade e aos postos de trabalho.

- As situações, tais como aquelas divulgadas pela publicação dos resultados da avaliação internacional dos estudantes (OCDE, 2001), que mostra que estudantes que não 
têm dificuldade em passar nas provas encontram dificuldades quando têm que usar os seus conhecimentos e habilidades para resolver situações desconhecidas.

- Resultados, como os do estudo realizado na Universidade de Málaga, revelam que os conhecimentos exigidos dos alunos no primeiro ciclo da ESO se tornam difíceis de serem respondidos nos últimos cursos universitários (Vera e Esteve, 2002). Deste fato, derivam-se várias questões problemáticas: a utilidade do conteúdo ministrado, sua seleção e, até mesmo, o significado dos testes de avaliação.

- A diferença entre o que, de acordo com a pesquisa conduzida sobre aprendizagem, pode ser aprendido e desenvolvido pelos meninos, meninas e adolescentes e o tipo de demanda cognitiva, intelectual e emocional que a escola apresenta. (Bransford e outros, 1999) e (Stoll e outros, 2003).

- A comprovação de que nos últimos cem anos, apesar dos esforços relacionados à inovação dos processos de ensino e aprendizagem, o ensino continua focado no professor. Em outras palavras, o professor fala muito mais do que os alunos no processo de ensino; ensino deve ser frontal; o docente se dirige a toda classe; o uso do tempo na sala de aula é, na maior parte das vezes, determinado pelo docente; os mobiliários geralmente estão organizados em filas e colunas, de frente para a lousa e para a mesa do professor (Cuban, 1993).

- Manifestações dos próprios estudantes, sobretudo, do nível secundário, mas também do ensino primário, sobre a diferença que surge, às vezes, entre os seus próprios interesses e motivações, e aqueles que são oferecidos pela escola (Sancho e outros, 2002).

- Situações de violência física e psíquica que algumas vezes aumentam, entre os próprios alunos, e entre eles e os professores.

A própria trajetória, às vezes contraditória, da sociedade que exige que os mais jovens aprendam valores (solidariedade, ética, esforço, etc.), quando as atuações públicas de empresários e políticos refletidas nos meios de comunicação apontam com frequência para o sentido oposto. 
Uma primeira consequência da consideração deste conjunto de fatos, que levam a argumentar a necessidade de se transformar profundamente a escola, é que, tendo em conta tais fatores, dada a complexidade social, a força dos sistemas de produção e dos meios de comunicação, a escola não pode se responsabilizar pela "educação integral", tal como consagra o primeiro ponto do LOGSE, de todas as crianças e adolescentes da população. A aceitação de tal responsabilidade, sem a garantia de se poder contar com os recursos adequados para assumi-la, coloca a escola em uma constante sensação de insatisfação.

\section{A escola como um lugar para recordar e escrever a própria história}

Muitas vezes, aparecem testemunhos sobre a necessidade de esquecer o que se aprendeu na escola, ou sobre a incapacidade de lembrar o que foi aprendido. Passamos muitos anos na escola e destinamos a ela uma quantidade muito grande de recursos, para obtermos uma influência tão incerta. Para muitas pessoas, ela acaba exercendo mais influência do que o esperado, e nem sempre no sentido desejado. Interiorizam-se, sobretudo, conhecimentos implícitos. O curriculum, chamado de desconhecido, na realidade, é o que se manteve por mais tempo, e mais se espalhou no espaço. Refiro-me à assimilação da docilidade, da paciência, da capacidade de suportar o sem sentido, respondendo apenas quando nos é solicitado, e somente o que está sendo solicitado, e com a resposta que se espera. Mas, dos conhecimentos considerados "básicos", "essenciais", "importantes", "imprescindíveis" e que, por conseguinte, tornam-se parte do curriculum escolar, diante do grande volume que está fora por vários motivos (Goodson, 2000), a destruição do esquecimento é o que costuma ir além do que nós mesmos gostaríamos. Acima de tudo, para aqueles cuja escola não ofereceu um lugar para aprender, e uma vez que a informação retida de uma memória incerta foi esquecida, estes se encontraram sem recursos para continuar a aprender e serem capazes de discutir o conjunto de informações diversificadas, que formam a vida na sociedade de hoje.

Desta forma, fala-se em porcentagens elevadas de analfabetos funcionais, visuais ou informáticos. Ou seja, são as pessoas que frequentaram a escola, aprenderam a ler e a 
escrever, e ainda obtiveram um diploma, por meio do qual, no mínimo, se supõe que tais indivíduos foram aprovados em muitos testes e estudaram entre oito e doze matérias por ano. No entanto, há pessoas que não entendem as notícias do jornal, nem os complementos científicos e culturais, nem as páginas econômicas. São pessoas com dificuldade de interpretar mensagens visuais de certa complexidade, que custam a entender e a realizar um conjunto de instruções que lhes permita programar um vídeo, ou qualquer eletrodoméstico programável, ou não conseguem ser usuárias de computador. Isto significa que oito, dez ou doze anos de educação escolar não prepararam um importante número de indivíduos para continuarem a aprender. Não predispuseram tais indivíduos a utilizar e desenvolver habilidades e conhecimentos em contextos que irão transformar suas vidas. Não incentivaram a curiosidade e a criatividade que lhes permitiria seguir acrescentando o seu saber, em um mundo onde o acesso à informação começou a ser um problema de excesso, em vez de falta. Em suma, o estágio escolar foi e continua sendo considerado como algo fechado em si mesmo: aprende-se na escola, para aprovar e satisfazer a família e os professores; ou para estar preparado para passar à etapa educativa seguinte. A ideia da escola como um lugar para reforçar os pilares da aprendizagem, a curiosidade, a constância, a crítica e o rigor está para se desenvolver de forma generalizada.

Nestes momentos, a curiosidade é morta pela necessidade de se "cobrir" alguns programas predeterminados, padronizados e volumosos. A assiduidade não cresce em lugares onde se permite "deixar o aprender para mais tarde", e a forma de avaliação permite que se deixe o estudo para a véspera do teste ou exame. A crítica não tem lugar se o conhecimento é representado como algo permanente, a partir de um único ponto de vista, e a partir de uma posição de verdade. E o rigor não prospera quando o material mais utilizado na escola são livros didáticos com mono-visão, muitas vezes, sem referências bibliográficas, em que o conhecimento é o que é, e não se desvia. Daí a necessidade de se transformar a escola em um lugar onde se aprende para o momento e para continuar aprendendo ao longo da vida. 


\section{Um lugar para se sentir emocionalmente salvo}

A configuração do mundo em que vivemos, que proporcionou o fenômeno do “desaparecimento da infância” (Elkind, 19881, Postman, 1988, Buckingham, 2001), fez com que muitos meninos, meninas e adolescentes tenham dificuldades para construir 0 seu próprio mundo, sobretudo, os pertencentes a grupos minoritários e de risco, mas também os restantes. Na própria escola, alguns estudantes podem se sentir em perigo ou magoados por ameaças intelectuais, reais ou imaginárias (Cummings, 2000).

Resolver esta situação implicaria em converter as escolas em lugares emocionalmente seguros e intelectualmente atraentes, para que cada aluno e aluna pudesse escrever sua própria história, e não aquela atribuída pelo seu meio social e cultural.

\section{Uma visão sobre a aprendizagem}

Nos últimos vinte anos, realizou-se um esforço considerável para se encontrar as chaves que permitam explicar como aprendemos, a fim de propiciar condições de aprendizagem mais favoráveis para todos os indivíduos, no período de formação básica.

Deste modo, como apontamos em um trabalho anterior (Sancho e Hernández, 1999), sabemos que os indivíduos aprendem quando:

- Envolvemo-nos em temas, problemas, atividades e tarefas que tenham relação com os nossos próprios interesses e preocupações.

- Trabalhamos em contextos de colaboração.

- Envolvemo-nos em processos de investigação.

- Refletimos ou avaliamos o nosso próprio processo de aprendizagem.

- Enfrentamos situações de aprendizagem problemáticas

- Relacionamos o que aprendemos nos centros de ensinamento com as experiências da vida cotidiana. 
- Exploramos questões e problemas desconhecidos para nós.

- Encontramos relações entre temas, disciplinas e áreas de interesse pessoal e social.

- Descobrimos que podemos compreender e comunicar tanto as coisas, acontecimentos e fenômenos em si, como seus aspetos, da forma melhor e da forma mais complexa.

Daí a importância de se levar em conta a investigação sobre a aprendizagem e suas implicações, para a elaboração e implementação dos melhores ambientes de ensino.

Bransford e outros (1999) levaram a cabo uma síntese exaustiva da investigação sobre a aprendizagem, realizada desde finais do século dezenove, momento em que se iniciava uma intenção sistemática de se estudar a mente humana de forma científica, ainda que seu enfoque seguisse a via da psicologia cognitiva clássica, fortemente relacionada com a estrutura lógica e com a compreensão consubstancial do conhecimento disciplinar acadêmico e científico. Neste sentido, as dimensões emocional e social da aprendizagem acabam apenas anunciadas e insuficientemente tratadas. Isto foi de fato percebido por Stoll e outros (2003), ao proporem a distinção fundamental entre a aprendizagem em geral e a aprendizagem que tem lugar na sala de aula e na escola.

Porém, na interação docente, não bastam somente as visões do aprendizado, também temos que levar em conta as visões da educação.

\section{Um conceito sobre ensino}

As teorias sobre aprendizagem não proporcionam uma receita simples para projetar ambientes de ensino que favoreçam os processos de aprendizagem, da mesma forma que a química informa, mas não diz como elaborar um fármaco. Em uma época em que todo mundo parece esperar muito da educação, uma contribuição fundamental das teorias da aprendizagem é que diferentes tipos de finalidades de aprendizagem requerem diferentes aproximações de ensino. Isto nos leva a crer que os ambientes de 
aprendizagem tradicionais, centrados no docente, mostraram-se insuficientes para propiciar as finalidades educacionais da maioria dos sistemas educativos contemporâneos. Deste modo, dar respostas às necessidades educacionais da sociedade atual implica em mudar a antiga imagem de um ensino fundamentalmente centrado nos professores, de modo a projetar ambientes de ensino diversificados, em que se comece a considerar com seriedade o papel dos alunos, o conhecimento, a avaliação e a comunidade.

Para Cuban (1993), existe uma série de indicadores observáveis, que permitem diferenciar o ensino centrado nos professores do ensino centrado nos alunos. Este segundo tipo de ensino se propõe a ser sensível às práticas culturais dos estudantes e ao efeito dessas práticas na aprendizagem em aula. Os professores, que realmente levam em conta os alunos, respeitam as suas práticas linguísticas porque elas são a base da aprendizagem posterior.

Os ambientes centrados nos alunos requerem um professor consciente de que os estudantes constroem os seus próprios significados, a começar pelas crenças, o entendimento e as práticas culturais trazidas pela escola. Se o ensino é entendido como a construção de uma ponte entre os materiais de estudo e os estudantes, os professores que focam nos alunos não perdem de vista nenhuma das duas partes desta ponte. Os professores tentam compreender o que os alunos sabem e podem fazer, além de seus interesses e paixões: eles conhecem cada estudante, o que lhes interessa, o que sabem e querem fazer. Os professores úteis "dão razão aos alunos", ao respeitar e entender as suas experiências prévias, assim como as suas compreensões, assumindo que podem ser a base para se construir caminhos para novos entendimentos.

Quando compreendemos os alunos e as alunas, as suas necessidades, desejos e características, estamos mais preparados para conceber um lugar para eles na escola. Saber trabalhar, a partir de uma perspectiva educativa, comportamentos relacionados a situações como, por exemplo, pobreza, sensação de perigo ou ameaça emocional, é fundamental para essa abordagem. Mas não se pode perder de vista que os ambientes somente centrados nos alunos nem sempre os ajudam a adquirir o conhecimento e as 
especialidades de que necessitam para viver em sociedade. Desta forma, os ambientes centrados no conhecimento trazem a necessidade de que alunos e alunas sejam pessoas bem informadas, cultas e que aprendam de um modo que lhes facilite a compreensão e a transferência (Bruner, 1981).

Os ambientes voltados para o conhecimento se entrecruzam com os que levam em conta os alunos, de modo que o ensino se inicia com o interesse não somente pelos preconceitos do estudante sobre os temas de estudo, mas também pela sua forma de aprendizado. Sem considerar cuidadosamente o conhecimento com o qual o aluno chega à situação de aprendizagem, é difícil prever o que ele entenderá, e como ele dará sentido à nova informação que lhe é apresentada.

Os ambientes centrados no conhecimento também dão atenção aos tipos de informação e atividades que ajudam o aluno a desenvolver a sua compreensão das disciplinas (Prawat at al, 1992). Além disso, coloca-se ênfase na adoção do sentido da informação, para ajudar o aluno a desenvolver processos de transferência, esperando que a nova informação faça sentido e pedindo esclarecimentos, caso a informação não faça sentido.

A ideia bastante difundida entre os professores da capacidade dos meninos, das meninas e, por vezes, dos adolescentes, de concretizar raciocínios complexos foi substituída pela evidência de que os mesmos são capazes de desenvolver os níveis estabelecidos de pensamento e raciocínio, quando lhe são fornecidas as condições necessárias para a realização dessa atividade.

As tentativas de se criar ambientes focados no conhecimento também levantam questões importantes sobre como promover a compreensão integrada de uma disciplina, ou sobre a forma de abordar os temas multidisciplinares. Muitos modelos de projeto curricular tendem a considerar o conhecimento e as habilidades mais como componentes desligados do que como conjuntos interligados. É por isso que a maioria dos currículos fracassa frequentemente, em vez de ajudar os estudantes a seguirem o seu caminho em uma disciplina, ou em um tema de conhecimentos relevantes. Um desafio para se conceber ambientes centrados no conhecimento é o de atingir o equilíbrio adequado 
entre as atividades necessárias para promover a compreensão e a autonomia das habilidades necessárias para se funcionar de forma eficaz, sem que o aluno se sinta sobrecarregado pelos requisitos que exigem atenção.

Mas, quem sabe, como já argumentamos em outra parte (Sancho e Hernández, 2001), o maior desafio para a planificação dos ambientes baseados no conhecimento seja o de transcender a ideia de que existe uma ordem psicológica orientada pelo construtivismo (deve-se adequar o que é ensinado para o nível de desenvolvimento do aluno) e uma ordem disciplinar vinculada a uma seleção de matérias e conteúdos que necessitem de uma sequência (uma reminiscência da ordem tecnológica), ordenada e estável, em um projeto curricular de escola, de ciclo, de sala de aula.

Ultrapassar essa concepção nos levaria a analisar o porquê desta ordem não ser “natural", como dizem alguns especialistas e como subscrevem muitos professores, e a buscar uma nova perspectiva, um novo foco para compreender e atuar na escola, um foco que não pode ser exclusivo, nem pode ser caracterizado por uma maneira única de gerir o conhecimento escolar. Este desafio pode ser tratado de diversas maneiras. Uma delas é por meio de um curriculum integrado, mas não como um objetivo em si, ou um modismo velho/novo, mas tendo-se em conta a forma como questionamos e revisamos o conhecimento escolar, o sujeito e sua relação com as diferentes realidades sociais. A visão do curriculum está presente em obras de outros autores, por exemplo, Hargreaves e outros (1998), Stoll e Fink (1999), Guarro (2001), Yus, (2001), Hernández (2001), como um meio de se encarar os novos desafios da educação para indivíduos em um mundo em mudança. Estes e outros autores destacam o esforço que se leva a cabo em muitos centros, que tentam deixar de serem arquipélagos, marcados pela isolação fragmentada produzida pelas disciplinas, organização departamental e o horário da "grade televisiva" (Sancho, 1997), para que possam encontrar pontes ou túneis que permitam a construção de projetos curriculares alternativos, em que este isolamento seja superado, e que trabalhem em favor da aprendizagem dos alunos. Projetos em que o eixo central não seja os conteúdos disciplinares, mas sim, a maneira de nos relacionarmos com eles e o relacionamento entre eles. 
Os ambientes de ensino que tentam satisfazer às necessidades dos alunos, além de focarem na aprendizagem e no conhecimento, deverão estar concentrados na avaliação. Os princípios chaves da avaliação são os de proporcionar oportunidades para realimentação e revisão, enquanto que o que é avaliado tem que ser coerente com as metas educativas, os processos e os recursos. Nesse sentido, o retorno é mais valioso quando os estudantes têm a oportunidade de utilizá-lo para rever o seu pensamento e suas emoções, enquanto trabalham em uma unidade ou projeto.

Um desafio para se levar a cabo práticas adequadas de avaliação implica em se mudar os modelos de muitos docentes, famílias, estudantes, pessoal de apoio e da Administração, sobre o significado da aprendizagem "efetiva”. Muitas avaliações desenvolvidas por docentes enfatizam a memorização de procedimentos e fatos. No entanto, as avaliações projetadas de forma apropriada podem ajudar os professores a se darem conta da necessidade de repensar suas práticas de ensino.

Mas, sobretudo, o sistema de avaliação deverá ser coerente com os objetivos educativos, estar presente em todo o processo de ensino e aprendizagem e utilizar recursos diversificados para que os alunos possam mostrar realmente o que sabem, de modo que a sua maneira pessoal de aprender se torne mais adequada. Deste modo, mesmo que pareça quase impossível se escapar da dimensão "punitiva” e justificativa da avaliação, professores e alunos podem encontrar neste processo um modelo de diálogo para calibrar seus avanços mútuos.

Finalmente, as teorias contemporâneas de aprendizagem sugerem que, à medida que ambientes de ensino estejam centrados na comunidade, favorecem-se as condições de aprendizagem para a maioria dos alunos. Considera-se especialmente importante a criação de situações em que uns podem aprender com os outros e levem a uma melhoria contínua do ensino.

Uma análise de ambientes de ensino, segundo a perspectiva da comunidade, também inclui uma preocupação com as conexões entre o contexto da escola e a comunidade em um sentido mais amplo, que leva em conta as famílias, os centros comunitários, as atividades extras curriculares e as empresas. Devemos recordar que, 
neste sentido, Dewey (1916) considerava que, do ponto de vista do menino, o grande desperdício na escola deriva de sua deficiência em utilizar sua experiência fora da escola, ficando o menino incapaz de aplicar na vida cotidiana o que aprende na escola. Este é um isolamento da escola, um isolamento da vida.

A conexão com especialistas fora da escola também pode ter uma influência positiva na aprendizagem escolar, porque proporciona aos estudantes e professores a oportunidade de interagir com pais, mães e outras pessoas interessadas no que se faz na escola. Para os alunos e docentes, pode ser motivador ter a oportunidade de partilhar o seu trabalho com outros. Nesses momentos, a proliferação das tecnologias da informação e da comunicação levantaram muitas expectativas, nem sempre fundamentadas, sobre a capacidade de ferramentas, como a Internet, de atingir "enfim" o sonho de se conectar a escola com o mundo (Sancho, 1999).

\section{Um conjunto de meios}

Ao longo da história, o surgimento de cada novo meio derivado do desenvolvimento das tecnologias da informação veio acompanhado de propostas de utilização pedagógica, mais ou menos fundamentadas. De qualquer maneira, também de forma consistente, a sua integração nos contextos de ensino não tem sido um processo fácil. Um importante volume de investigação desenvolvido para identificar "o melhor meio de ensino" nos proporcionou uma lição fundamental: não existem meios superiores a outros, apesar de a técnica utilizada por alguns deles para armazenar e transmitir as mensagens possa ser considerada superior. Clark (1983).

Esta constatação se conecta a uma evidência de que o surgimento de novos suportes para a informação não implicam no desaparecimento dos já existentes, e que cada um deles tem um conjunto de funções diferenciadas. Daí o interesse de se levar em consideração o conjunto de meios de informação e comunicação disponível, na configuração dos ambientes de ensino e aprendizagem. 


\section{Um cenário organizacional}

Para que a escola esteja preparada para enfrentar as necessidades educacionais atuais, a sociedade terá de reconhecer a importância da educação para o progresso, não somente material e moral da humanidade, mas também considerar que as alterações na educação terão que ser mais substanciais, não somente em relação ao capítulo das tecnologias da informação e da comunicação, mas também em todos os aspetos implicados no ensino e na aprendizagem. Portanto, as alterações teriam que tratar das tecnologias da educação.

Se fosse assim, as escolas poderiam ser lugares abertos, com diferentes ambientes de aprendizagem, configurados segundo os métodos mais apropriados para se alcançar as finalidades educacionais e os recursos mais adequados. Pessoas com idades distintas poderiam assistir a estes centros e complementariam a sua formação em casa ou em outros lugares. Os centros seriam dotados de todas as ferramentas disponíveis na sociedade, incluindo as mais avançadas tecnologias da informação e da comunicação. Além disso, contariam com um conjunto diversificado de especialistas educacionais que desempenhariam as distintas atividades necessárias. Os horários destes especialistas se prolongariam, por meio de turnos e ao longo do dia, assim como em outras instituições. Alguns deles poderiam realizar parte do trabalho em casa. A organização do espaço necessário para se por em prática esta visão de um ambiente diversificado está representada no gráfico 1. 


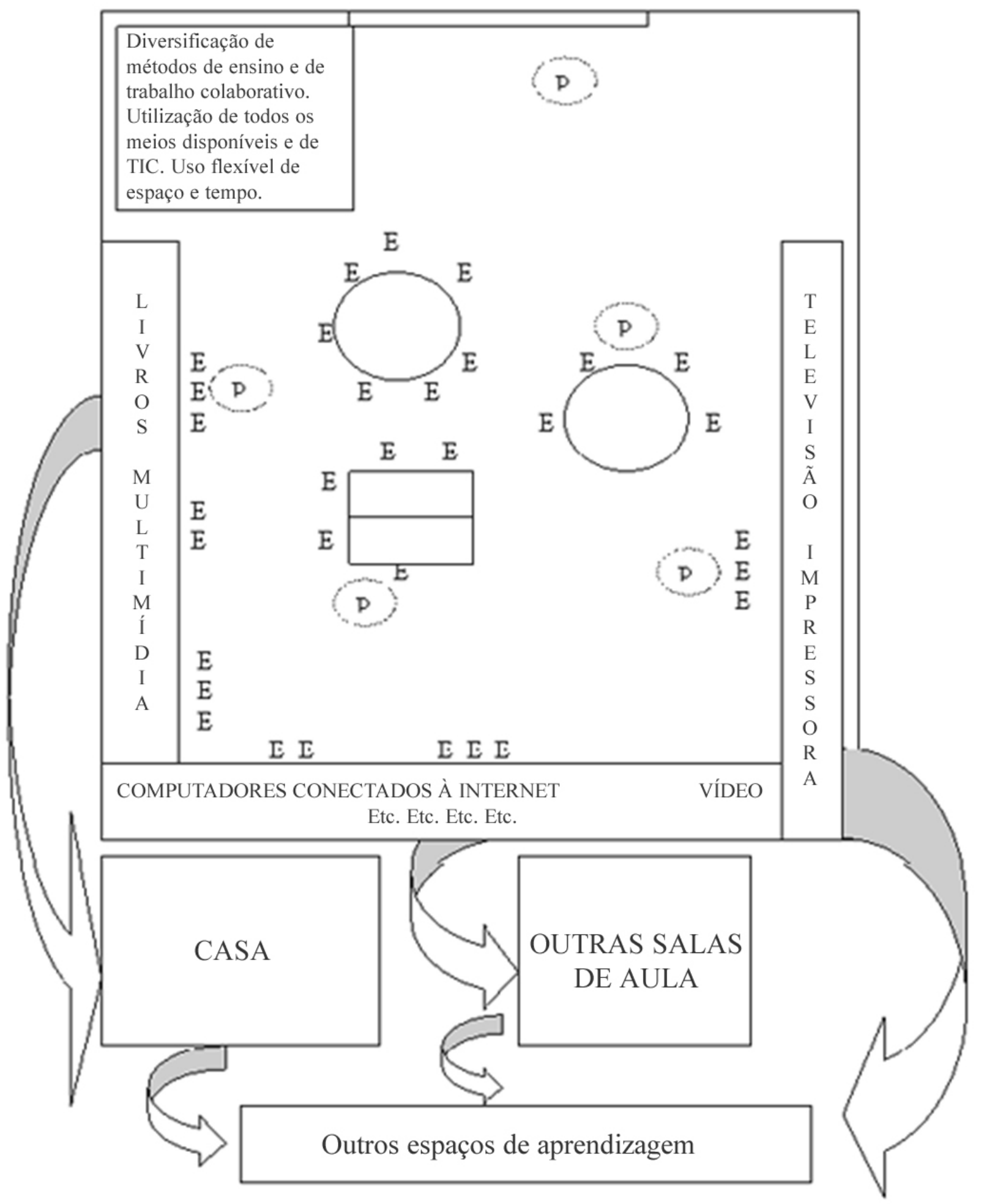

Gráfico 1 - Representação de uma proposta para ambientes de aprendizagem diversificados. 
Os pontos chave associados a esta forma de se conceber a escola, as dificuldades e, por sua vez, as maiores fontes de elaboração de conhecimento pedagógico em ação se encontram na:

- Planificação do conjunto de atividades diversificadas do centro, para que se possa garantir uma formação equilibrada de todos os alunos;

- O desenvolvimento ou reutilização de materiais de ensino, fazendo uso das tecnologias disponíveis;

- Acompanhamento e avaliação dos alunos.

A participação ativa e responsável nas diferentes tarefas e na própria organização do centro de todos os implicados seria um dos elos condutores deste tipo de instituição.

Esta forma de entender o ensino e a aprendizagem, em concordância com as próprias necessidades e desafios da sociedade atual, precisará de especialistas educacionais, com uma preparação pedagógica que fomente uma visão multidisciplinar e integrada do conhecimento, bem como sua autonomia e sua própria capacidade de aprender. Do mesmo modo, o conjunto de pessoas que se comprometem com novas profissões relacionadas com o projeto e desenvolvimento de aplicações informatizadas para a educação terão de contar com uma preparação pedagógica que lhes permita entender a natureza dos problemas no âmbito de trabalho. Neste contexto, a formação dos professores torna-se um tema fundamental.

\section{Conclusões}

A adoção de uma perspectiva multidisciplinar em relação à problemática da educação no mundo atual implica em se repensar os conceitos disciplinares tradicionais, ou seja, um convite para se ultrapassar barreiras e para tratar dos problemas a partir de sua complexidade. Assim, tal perspectiva pode ser entendida como uma das opções mais adequadas para se realizar propostas e projetos educativos que evitem o reducionismo técnico e levem em consideração o conjunto das dimensões que interagem nas situações de ensino e aprendizagem. 


\section{Referências}

BRANSFORD, J. D. Et al. (1999) How people learn: brain, mind, experience, and school. National Academy Press. Washington, D.C.

BRUNER, J. (1981) The organization of action and the nature of adult-infant transaction. In D.d'Ydevalle y W. Lens (Eds.) Cognition in Human Motivation and Learning. Erlabaum. Hillsdale.

BUCKINGHAM, D (2000) After the Dead or Childhood. Growing up in the age of electronic media. Polity Press. Oxford.

CASTELLS, M. (1988) La era de la Información. Economía, sociedad y Cultura. Vol. 2 El poder de la identidad. Alianza. Madrid.

CLARK, R.E. (1983) Reconsidering Research on Learning from Media. Review of Educational Research, 5314, 445-459.

CONTRERAS, J. (1990) Ensenanza, currículum y profesorado. Akal. Madrid.

CUBAN L. (1993) How teachers taught: constancy and change in American classrooms, 1890-1990. Teachers College Press. Nueva York.

CUMMINGS, C. (2000) Winning Strategies for Classroom Management. Association for Supervision and Curriculum Development. Alexandria.

DAVIES, Y. K. (1996) Educational Technology: Archetypes, Paradigms and Models. En D. P. Ely y T. Plomp (1999) Classic Writings on Instructional Technology. Libraries Unlimited, Inc. Englewood, Colorado.

DEWEY, J. (1916) Democracy and Education. Macmillan. New York.

ELKIND, D. (1981) The Hurried Child: growing to fast too soon. Addison-Wesley Pu. Co. Reading.

ELLIOTT, J. (1990) La investigación-acción en educación. Morata.Madrid.

FOUCAULT, M. (1991) Genealogía del racismo. La Piqueta. Madrid.

FOUCAULT, M. (1992) La arqueología del saber. Siglo XXI. Mexico. 
GIBBONS, M. y OTROS. (1995) The new Production of Knowledge. Sage Publications. GOODSON, I. (2000) El cambio en el currículum.. Octaedro. Barcelona.

GUARRO, A. (2001) El currículum democrático e integración curricular. Cooperación educativa, 59/60, 57-63.

HARGREAVES, A. Y OTROS (1998) Repensar la educación para los adolescentes. Octaedro. Barcelona.

HERNANDEZ, F. (2001) El currículum integrado: de la ilusión del orden a la realidad del caos. Cooperación educativa, 59160, 79-85.

MORIN, E. (2000) La mente bien ordenada. Seix Barral. Barcelona.

NOBLE, D. D. (1991) The Classroom Arsenal: Military Research, Information Technology and Public Education. The Falmer Press. London.

OECD (2001) Knowledge and Skills for Life. First Results from OECD Programme for International Students Assessment (PISA) 200. OECD. París.

POSTMAN, N. (1988) La desaparición de la ninez. Círculo de Lectores. Barcelona.

PRAWAT, R.S. et al. (1992) Teaching Mathematics for understanding: Case study of four fitth-grade teachers. Elementary School Journal, 93, 145-152.

SANCHO J. Ma (1999); Tecnologías de la Información o Tecnologías de la Información? Revista Educar, 25, 205-228.

SANCHO J. Ma (2000) Diversificar los espacios de ensenanza. Cuadernos de Pedagogía,290, pp. 54-57.

SANCHO J. Ma (2002) Proyecto docente. Universidad de Barcelona. Barcelona.

SANCHO J. Ma y HERNÁNDEZ, F. (1999) Study of Teacher Practices and Assessment of Training Needs. Informe policopiado. El Banco Mundial.

SANCHO J. Ma y HERNÁNDEZ, F. (2001) Perspectivas de cambio sobre la ensenanza y el aprendizaje. Simposio sobre Itinerarios de Cambio en la Educación. Barcelona 15-16 de marzo. http:Ilxiram.doe.d5.ub.esIcanvi. 
SANCHO J. Ma y OTROS (2002) Analyses of Users Needs. European Commission. School+ More than a Platform to Build the School of Tomorrow. (IST-2000-25162). Luxembourg.

SANCHO, J. Ma (1997) La comprensión de las problemáticas de la educación escolar. AULA De Innovación Educativa, 67, 80-85.

SANCHO, J. Ma (1998) Enfoques y funciones de las nuevas tecnologías para la información y la educación: lo que es no es lo que parece. En J. de Pablos y J. Jiménez (Coord.) Nuevas tecnologías. Comunicación Audiovisual y educación. Cedecs. Barcelona.

SIMON, H. A. (1969) The Sciences of Artificial.. MIT.. Cambridge.

SOTELO, I. (1987) Poder y técnica. Revista de Occidente, 71, pp. 5-16.

STEINBERG, Sh. R. y KINCHELOE, J. L. (1997) Kinderculture. The Corporate construction of Childhood. Westview Press. New York.

STOLL, L. y FINK, D. (1999) Para cambiar nuestras escuelas. Octaedro. Barcelona.

STOLL, L., FINK, D. y EARL, L (2003) It's About Learning (and It's About Time. De próxima publicación por la editorial Octaedro). Routledge. Londres y Nueva York.

VERA, J. y ESTEVE, J. M. (2002) Un examen a la cultura escolar. Cuadernos de Pedagogía, 309, pp.85-89.

YUS, R. (2001) Educación integral. Una educación holística para el siglo XXI. Vol. I y II. Desclée. Bilbao.

Universidade do Estado de Santa Catarina - UDESC Programa de Pós-Graduação em Educação - PPGE Revista Linhas Volume 14 - Número 27 - Ano 2013 revistalinhas@gmail.com 